\title{
E3 Ubiquitin-Protein Ligase RNF139
}

National Cancer Institute

\section{Source}

National Cancer Institute. E3 Ubiquitin-Protein Ligase RNF139. NCI Thesaurus. Code C30127.

E3 ubiquitin-protein ligase RNF139 (664 aa, 76 kDa) is encoded by the human RNF139 gene. This protein plays a role in protein ubiquitination, inhibition of cell proliferation and cell cycle regulation. 